\title{
A computerized prospective audit of cardiopulmonary resuscitation in the accident and emergency department
}

\author{
J. WARDROPE, A. C. CROSBY, D. G. FERGUSON AND \\ D. L. EDBROOKE
}

Department of Accident and Emergency Medicine, Royal Hallamshire Hospital, Sheffield, England

\section{SUMMARY}

A prospective survey of cardiopulmonary resuscitation is in progress in the Accident and Emergency Department of the Royal Hallamshire Hospital. During the 12 months from January 1985 to January 1986, 123 cardiac arrests were treated in the accident department. Ninety of these arrests occurred outside the hospital; nine of these patients survived to leave hospital. Of the 33 people arresting in the department, 10 survived to leave hospital. The causes of death are presented.

\section{INTRODUCTION}

There has been much publicity recently regarding cardiopulmonary resuscitation with criticism of the resuscitation skills of doctors (Casey, 1984; Skinner et al., 1985). At the same time, the training of ambulance crews in advanced life-support techniques and the introduction of widespread training of basic cardiopulmonary resuscitation in the community (Vincent $e t$ al., 1984) make it likely that more victims of cardiac arrest will present to the accident and emergency department. It is essential that we are well equipped and trained in resuscitation.

Audit of one's performance is necessary to check that errors are not occurring or, if they are, to take steps at an early stage to correct these errors.

Correspondence: Mr f. Wardrope, Senior Registrar, Department of Accident and Emergency Medicine, Royal Hallamshire Hospital, Glossop Road, Sheffield S10 2fF, England 


\section{SUBJECTS}

The Accident and Emergency Department of the Royal Hallamshire Hospital sees 57000 new patients each year. The survey includes all patients on whom the ambulance crew were performing basic cardiopulmonary resuscitation (CPR) on arrival at the department. Although most of the out-of-hospital arrests were witnessed events, somछ were found in a collapsed state and the duration of the arrest unknown.

A cardiac arrest was defined as an unconscious patient with no palpable major pulse Three patients arrested in the Department and resuscitation was not performed. These patients were old and had other non-cardiac pathology.

\section{METHODS}

During the first week of their attachment to the department, the senior house officer@ were given training in advanced cardiopulmonary resuscitation techniques. Each arres $\varrho$ was managed along the guidelines given by the Resuscitation Council of Great Britain(Resuscitation Council (UK), 1984). This provides protocols for each of the major types of arrest: ventricular fibrillation, asystole and electromechanical dissociation. For eacloo of these, a flow chart is provided detailing treatment and drugs to be given in a specifie order (Fig. 1). On arrival of a cardiac arrest in the Department, the airway was managed using high-flow oxygen delivered by 'bag and mask', and venous access via periphegalo veins, if possible. Clothes were removed and the rhythm noted using the paddles of defibrillator while a brief history was obtained from the ambulance crew. Treatmento proceeded according to the guidelines unless the history dictated another course of action.

Patients with chest pain are routinely attached to a monitor on arrival in th department in order to diagnose and treat any 'in-hospital arrest' as quickly as possible $\overrightarrow{\overrightarrow{\vec{*}}}$

During an arrest, a member of the nursing staff recorded each treatment as it was given. The doctor in charge of the arrest then completed a proforma, recording the patient details, condition of the patient on arrival, and the conduct and outcome of the arrest. The patient was then followed up until death or discharge from hospital. Details of neurological status on discharge were obtained from the inpatient records.

The Accident Department has a BBC micro-computer fitted with a terminal ROM. chip which converts the micro into a remote terminal of the University of Sheffiel mainframe computers. The information was stored on the Prime computer using the 'Prime Information' data-base software. The information has been registered under the data protection act.

The chi-squared test with Yates' modification for small numbers was used for the statistics in Table 4. 


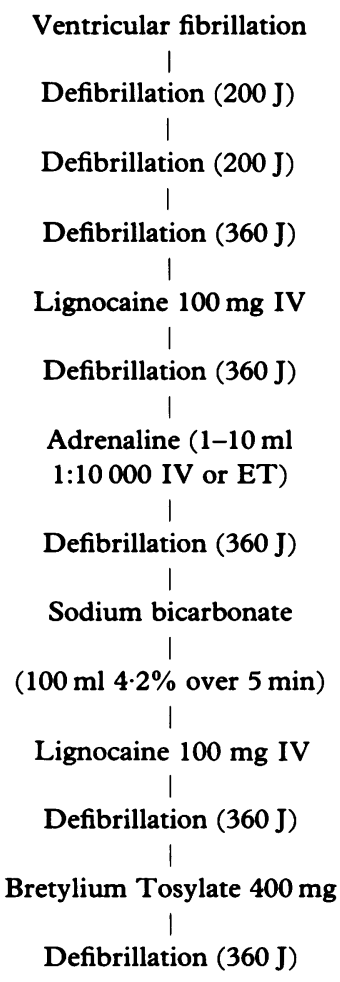

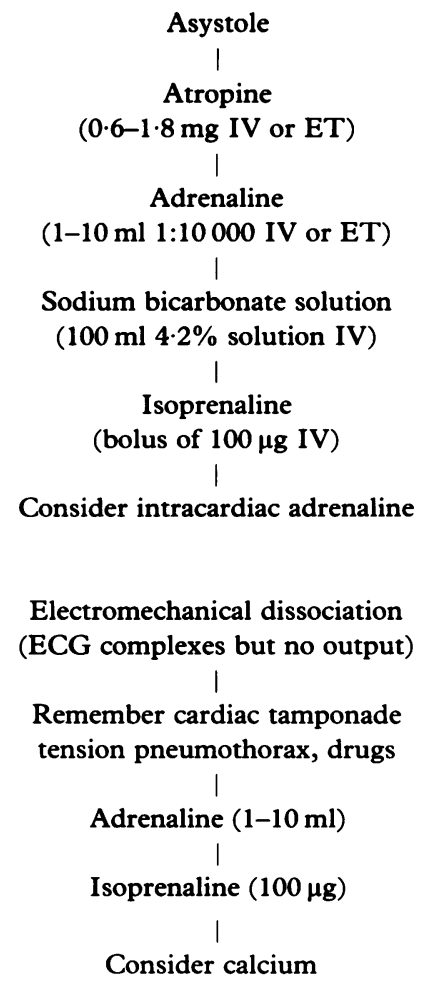

Fig. 1 The guidelines for the management of cardiac arrest (ET: via endotracheal tube; IV: intravenously).

\section{RESULTS}

\section{Cause of cardiac arrest}

There were 123 cardiac arrests during the 12 -month period. The majority of these arrests were due to 'medical' conditions. Most of these were sudden collapse/chest pain. 'Asthma' was quite often given as the history (10 patients) and was the probable cause of the arrest in eight. All of these asthmatic patients were over $\mathbf{4 0}$ years of age and had arrested outside hospital. Although asthma was given as the history, some were undoubtedly chronic obstructive airways disease.

Three cases were due to trauma. 


\section{Condition of patients on arrival}

Seventy-two $(80 \%)$ of the out-of-hospital arrests had dilated pupils and no spontaneous respiration on arrival in the Department. Of the nine patients surviving to hospital: discharge, three had responsive pupils and spontaneous respiration, three had reactive? pupils but no spontaneous respiration, and three had neither spontaneous respiration nor reactive pupils on arrival in the Department.

Twelve of the out-of-hospital arrests had CPR performed by a member of the public One of these patients survived to leave hospital.

\section{Outcome}

Table 1 reviews the results of the arrest with reference to whether the arrest occurred outwith hospital or within the Accident and Emergency Department. Cardiac output was restored in $47 \%$ of all arrests, with $37 \%$ surviving to hospital admission. The overall survival to discharge from hospital was $15.4 \%$, with the survival of an in hospital arrest $30 \%$ and an out-of-hospital arrest $10 \%$.

Table 1 Outcome of arrest with site of arrest (percentages of the number of arrests in the group)

\begin{tabular}{|c|c|c|c|c|}
\hline Arrest site & Number & Output & Admitted & Discharged \\
\hline In-hospital & 33 & $24(73)$ & $17(52)$ & $10(30)$ \\
\hline Out-of-hospital & 90 & $36(40)$ & $28(31)$ & $9(10)$ \\
\hline
\end{tabular}

Of patients surviving to discharge after an out-of-hospital arrest, six arrested in the ambulance during transport to hospital, one arrested in a private car and was drive directly to the hospital, one arrested at a nursing conference and had CPR commence® immediately, and one collapsed in a bingo hall and was pulseless on arrival of the्ٍ ambulance crew. All the long-term survivors of out-of-hospital arrest were in ventricus lar fibrillation at the outset. Thirty-one of the out-of-hospital arrests were in asystole of arrival and none survived to hospital discharge.

Table 2 shows the relationship of age to survival.

Table 2 Number of arrests, and number and percentage surviving to hospital discharge by age

\begin{tabular}{lccc}
\hline Age & No. & $\begin{array}{c}\text { No. } \\
\text { surviving }\end{array}$ & $\begin{array}{c}\text { Percentage } \\
\text { surviving }\end{array}$ \\
\hline $20-29$ & 5 & 1 & $20 \cdot 0$ \\
$30-39$ & 3 & 0 & 0 \\
$40-49$ & 15 & 2 & $13 \cdot 3$ \\
$50-59$ & 22 & 8 & $36 \cdot 4$ \\
$60-69$ & 50 & 6 & $12 \cdot 0$ \\
$70-79$ & 21 & 2 & $9 \cdot 5$ \\
$80-89$ & 7 & 0 & 0 \\
\hline
\end{tabular}


The survivals for the arrest rhythms are shown in Table 3. The success rates for the presenting arrythmia shows that $29.3 \%$ of patients with VF or VT were discharged from hospital, whereas only one case of asystole (sinus arrest) survived to discharge.

As might be expected, those patients resuscitated quickly had a much greater chance of survival (average time for restoration of stable cardiac output was 10 minutes for those discharged but 20 minutes for other cases).

Table 3 Number of arrests, number and percentage surviving to ward admission and discharge with arrest rhythm

\begin{tabular}{lccc}
\hline & No. & Admitted & Discharged \\
\hline Ventricular fibrillation & 59 & $32(54 \%)$ & $16(27 \%)$ \\
Asystole & 45 & $8(18 \%)$ & $1(2 \%)$ \\
Ventricular tachycardia & 2 & 2 & 2 \\
Bradycardia, EMD, idioventricular rhythm & 17 & 3 & 0 \\
\hline
\end{tabular}

\section{Airway}

During the survey, 20 patients had their airway maintained by bag and mask. Eleven of these patients survived to discharge. Of those 103 requiring intubation, only eight were discharged. In the last 6 months of the survey, vomit was found in the pharynx of 22 patients out of 59 cases of out-of-hospital arrest.

\section{Drug therapy}

The use of drugs was recorded and this allowed us to monitor adherence to the guidelines. For example, the recommended drugs for the treatment of asystole are atropine followed by adrenaline. During the last 6 months of the survey, there were 28 cases of asystole, and 14 of these had atropine as first drug and adrenaline as second drug. In four patients, the adrenaline was given first followed by atropine, three cases were given calcium gluconate followed by adrenaline, and two cases were given atropine and isoprenaline. Two cases received no drugs and one case naloxone. Two cases were given atropine followed by lignocaine.

The effectiveness of drugs could be also be studied. For example, bretylium tosylate is used in the treatment of refractory VF. It was used in 13 such cases where lignocaine (nine cases, $200 \mathrm{mg}$; one case, $150 \mathrm{mg}$; three cases, $100 \mathrm{mg}$ ) had not helped to achieve defibrillation. In 10 of these cases, defibrillation was successful and cardiac output returned. Eight cases were admitted to the wards and four were discharged home.

\section{Blood gases}

Blood gases were recorded where possible. This was usually on patients regaining cardiac output. All $\mathrm{PaO}_{2}$ measurements were greater than $2 \mathrm{kPa}$, with the exception 
of three samples with $\mathrm{PaO}_{2}$ less than $8 \mathrm{kPa}$. Two of these were asthmatic arrests and the other probably a venous sample. The $\mathrm{pCO}_{2}$ and $\mathrm{pH}$ were used to evaluate the presence and type of acidosis. Table 4 shows the influence of the type of acidosis of survival. No $\stackrel{\varnothing}{\circ}$ patient with a pure metabolic acidosis survived more than 24 hours, but 17 out of $25 \Rightarrow$ patients with normal $\mathrm{pH}$ or a respiratory or mixed acidosis survived more than 24 hours $(0.01>P>0.001)$.

Table 4 Length of survival and blood gas analysis

\begin{tabular}{|c|c|c|c|c|c|}
\hline \multirow[b]{2}{*}{ Acid/base status } & \multicolumn{5}{|c|}{ Survival (hours) } \\
\hline & $<1$ & $1-6$ & $6-24$ & $>24$ & Discharge \\
\hline $\mathrm{pCO}_{2}<6 \mathrm{kPasc} ; \mathrm{pH}>7 \cdot 3$ (normal) & 0 & 2 & 1 & 0 & 4 \\
\hline $\begin{array}{l}\mathrm{pCO}_{2}<6 \mathrm{kPasc} ; \mathrm{pH}<7.3 \text { (metabolic } \\
\text { acidosis) }\end{array}$ & 6 & 1 & 0 & $\mathbf{0}$ & 0 \\
\hline $\begin{array}{r}\mathrm{pCO}_{2}>6 \mathrm{kPasc} ; \mathrm{pH}<7 \cdot 3 \\
(\text { respiratory } / \text { mixed acid })\end{array}$ & 1 & 1 & 3 & 7 & 6 \\
\hline
\end{tabular}

\section{Cause of death}

Post-mortem examination was requested when possible but, as most of these cases we $\vec{\ominus}_{\infty}$ reported to the Coroner, it was his decision whether a post mortem was needed. Fift $\operatorname{six}(61 \%)$ of the deaths had a post-mortem examination. Where this was not carried out the cause of death was taken from the hospital notes or the death certificate.

Major complications were rare. The most worrying finding was the relatively high incidence of pneumothorax occurring in asthmatic arrests. All of these arrests occurred out of hospital, usually with a history of sudden deterioration in breathing. It is not $\overrightarrow{\vec{A}}$ possible to say whether the arrest was due to the development of pneumothorax or if the $\frac{\circ}{3}$ pneumothorax was due to the resuscitation.

The only other pneumothorax found was a complication of central venous cannulation. There were two inadvertent arterial cannulations during central venous cannulation.

There was one case of stomach rupture.

\section{DISCUSSION}

The aim of the survey is to give an over-view of cardiac arrest in the accident and $\%$ emergency department and to begin to assess the methods used in our treatment. The $\mathcal{N}^{N}$ guidelines of the Resuscitation Council were adopted since it is important that junior $\mathrm{C}$ staff have clear instructions on management of these critical situations, and to give some continuity so that they become 'routine' rather than fraught with indecision and $\stackrel{0}{\circ}$ anxiety. Of course, it is impossible to stick rigidly to the guidelines and it is emphasized $\stackrel{\mathscr{\rho}}{\rightarrow}$ 
Table 5 Causes of death

\begin{tabular}{lc}
\hline Cause of death & $\begin{array}{c}\text { No. of } \\
\text { cases }\end{array}$ \\
\hline Myocardial infarction ( 79 cases) & \\
Triple-vessel coronary artery disease & 30 \\
'Ischaemic heart disease' (no PM) & 28 \\
Single-vessel coronary artery disease & 9 \\
Cardiac tamponade due to MI & 3 \\
Left ventricular failure due to MI & 4 \\
Hypoxic brain damage secondary to MI & 2 \\
Pulmonary embolus secondary to MI & 2 \\
MI secondary to aortic stenosis & 1 \\
& \\
Asthma/C.O.A.D. (8 cases) & \\
Pneumothorax & 3 \\
Hypoxic brain damage & 3 \\
Respiratory failure & 2 \\
& \\
Others (17 cases) & \\
Injury (2 head, 1 multiple) & 3 \\
Dissecting aneurysm (2 cardiac tamponade) & \\
Sub-arachnoid haemorrhage & 3 \\
Poisoning (carbon monoxide, distalgesic) & 2 \\
Pulmonary embolus & 2 \\
Abdominal aortic aneurysm & 2 \\
Seppy mitral valve & 1 \\
Tracheobronchitis & 3 \\
\hline
\end{tabular}

that these are guidelines and not strict protocols. A cardiac arrest does not always fall into straightforward ventricular fibrillation, asystole or electromechanical dissociation and often all three groups are seen in one arrest. Furthermore, in about $25 \%$ of cases, the primary pathology will not be cardiac and the treatment will have to be directed to the underlying pathology at the same time as the cardiac resuscitation. The guidelines are probably not perfect, but one must begin with some definite policy and then evaluate this treatment.

It is difficult to compare the results of cardiac arrests in different situations and in different countries. The criteria for admission into any given series may differ and 30$50 \%$ of cases may be excluded (Thompson et al., 1985).

The series presented includes all patients with the diagnosis of cardiac arrest as defined by lack of cardiac output and no response to commands, spontaneous speech or eye opening apart from the three cases mentioned earlier, on whom resuscitation was not attempted.

For those arrests out of hospital all patients undergoing cardiac massage by the ambulance crew were included. Adherence to these criteria meant that one case with a sinus arrest in the accident and emergency unit was included, even although she would have survived without any treatment, but many more cases with very poor prognoses 
are included. Indeed, the case of carbon monoxide poisoning was noted to be 'difficult to intubate' and this was due to rigor mortis! However, these are extremes of the $\frac{3}{3}$ spectrum.

The results of 'in-department' arrest compare favourably with other reported series $\vec{F}$ of in-hospital cardiac arrest (DeBard, 1981; Hanson, 1984) and are similar to other accident and emergency departments such as Edinburgh, where $37 \%$ of their indepartment' arrests were discharged from hospital (Robertson \& Little, 1984).

Similarly, the results of the 'out-of-hospital' arrests compare almost exactly with $\stackrel{\mathbb{ळ}}{\circ}$ other cities whose ambulance service is trained only in basic resuscitation (Gudjonsson $\%$ et al., 1982). However, the results are inferior to those series from cities with advanced- $\vec{o}$ trained ambulance crews where survival rates of $17 \%$ (Rowley et al., 1985) to $27 \%$ (Thompson et al., 1985) are reported, or cities with a high proportion of arrests $\stackrel{\omega}{\omega}$ attended by members of the public trained in CPR and a fast-response paramedic $\stackrel{\oplus}{3}$ system where survival rates of $43 \%$ have been achieved (Thompson et al., 1979). It $\dot{\omega}$ would appear that the most effective way of increasing the success rate for out-of- $\omega$ hospital arrest is the advanced training of ambulance personnel to ensure adequate CPR $\vec{c}_{\tilde{D}}^{\text {o }}$ and speedy defibrillation in the field. This approach is now gaining wider acceptance in $ᄋ$ the United Kingdom and, indeed, the first advanced-trained ambulance personnel will $\vec{c}$ be working in Sheffield by summer 1986. It will be some time before enough of these $\frac{\Phi}{\Phi}$ personnel are trained to provide full cover for the city but it will be very interesting to $\frac{\pi}{\pi}$ follow the results of these advanced teams compared with our present results.

There has been some controversy recently regarding the management of the airway (Scott, 1986; Steedman, 1986). Our results show that the correct use of bag and mask $8 \overrightarrow{8}$ satisfactory for the initial management of cardiac arrest. However, it must also be note that a high percentage of out-of-hospital arrests have vomited and, in these circunt? stances or if prolonged resuscitation is needed, endotracheal intubation is necessary. The fact that many cardiac arrests are secondary to another pathology must be borne in mind by the accident doctor. Cases of cardiac tamponade, tension pneumothorax and severe hypovolaemia can survive if treated quickly and effectively.

However, there remains much to be done in the field of basic CPR research. There $\stackrel{9}{3}$ are many animal studies but very few on the mechanics of CPR in the human with a few notable exceptions (Nieman et al., 1984; Chandra et al., 1981). Accident departments are going to deal with many arrests and these must be dealt with efficiently and speedily, but there is also great potential for improving our training, methods and drug treatment, and this calls for basic research into this critical problem.

\section{ACKNOWLEDGEMENTS}

We would like to thank the Senior House Officers and the Nursing staff of the Accident ${ }^{\text {* }}$ and Emergency Department of the Royal Hallamshire Hospital for their work and cooperation, the University of Sheffield Computing Department for the use of the computing facility, and Dr D. J. Fothergill for her help with the manuscript. 


\section{REFERENCES}

Casey W. F. (1984) Cardiopulmonary resuscitation: a survey of standards among junior hospital doctors. fournal of the Royal Medical Society 77, 921-4.

Chandra N., Snyder L. D., Myron L. \& Weisfeldt M. L. (1981) Abdominal binding during cardiopulmonary resuscitation in man. Fournal of the American Medical Association 246, 351-6.

DeBard M. L. (1981). Cardiopulmonary resuscitation: analysis of six years' experience and review of the literature. Annals of Emergency Medicine 10, 408-16.

Gudjunsson H., Baldvinsson E. \& Oddsson G. (1982) Results of attempted cardiopulmonary resuscitation of patients dying suddenly outside hospital in Reykjavik and surrounding area, 1976-1979. Acta Medica Scandinavica 212, 247-51.

Hanson G. C. (1984) Cardiopulmonary resuscitation: chances of success (editorial). British Medical fournal 288, $1324-5$.

Nieman J. T., Rosborough J.P., Ung S. \& Criley J. M. (1984) Haemodynamic effects of continuous abdominal binding during cardiac arrest and resuscitation. American fournal of Cardiology 53, 269-74.

Resuscitation Council (UK) (1984) Cardiopulmonary resuscitation. Stavanger, Asmund S. Laerdal.

Robertson C. E. \& Little K. (1984) Cardiopulmonary resuscitation in the accident and emergency department. Archives of Emergency Medicine 1, 17-22.

Rowley J. M., Garner C., Handy M. \& Hampton J. R. (1985) Simple training programme for ambulance personnel in the management of cardiac arrest in the community. British Medical fournal 291, 1099-101.

Scott D. B. (1986) Endotracheal intubation: friend or foe? British Medical fournal 292, 157.

Skinner D. V., Camm A. J. \& Miles S. (1985) Cardiopulmonary resuscitation skills of preregistration house officers. British Medical fournal 290, 1549-50.

Steedman D. J. (1986) Endotracheal intubation: friend or foe? British Medical fournal 292, 409.

Thompson B. M., Stueven H. A. \& Mateer J. R. (1985) Comparison of clinical CPR studies in Milwaukee and elsewhere in the United States. Annals of Emergency Medicine 14, 750-4.

Thompson R. G., Hallstrom A. P. \& Cobb L. A. (1979) Bystander initiated resuscitation in the management of ventricular fibrillation. Annals of Internal Medicine 90, 737-40.

Vincent R., Martin B. \& Williams G. (1984) A community training scheme in cardiopulmonary resuscitation. British Medical fournal 288, 617-20.

Received 21 April 1986; accepted 25 May 1986 